\title{
Orientation invariance of shape recognition in forebrain-lesioned pigeons
}

\author{
Juan D. Delius ${ }^{1}$ and Valerie D. Hollard ${ }^{2}$ \\ ${ }^{1}$ Experimentelle Tierpsychologie, Psychologisches Institut, Ruhr-Universität Bochum, Bochum (F.R.G.) and ${ }^{2}$ Department of \\ Psychology, University of Auckland, Private Bag (New Zealand)
}

Key words: Orientation invariance; Shape recognition; Forebrain lesion; Discrimination; Learning; Pigeon

\begin{abstract}
Pigeons were trained to perform a visual orientation invariance task consisting of shape matching-to-sample or oddity-fromsample discriminations where the comparison forms differed in orientation from the sample forms, and the odd comparison forms were always a mirror image of the sample. They then received lesions affecting the visual projection area within the anterior hyperstriatum or the dorsal neostriatum, a control area with no known visual function. Both groups of birds evinced minor transient postoperative deficits of similar magnitude during the shape recognition task under orientation invariance conditions when the habitual training forms were used. When novel forms were introduced, the performance of hyperstriatal pigeons was significantly worse than that of the neostriatal pigeons, but still well above chance. The introduction of a delay between the offset of the sample and the onset of the habitual comparison stimuli did not yield any differential effect. It is concluded that orientation invariance of pattern recognition performance of birds, in contrast to that in mammals, is probably a midbrain, optic tectum function.
\end{abstract}

\section{INTRODUCTION}

In earlier experiments it was shown that pigeons are able to solve a certain visual pattern recognition task involving rotated visual forms more efficiently than humans ${ }^{12}$. When having to discriminate between visual shapes and their mirror-images, the decision times and/or the error rates of humans increases as a function of the angular orientation disparity between the two shapes. The information processing operation that humans perform to achieve this rotational invariance task is known as mental rotation ${ }^{26}$ and it has been shown that the speed of rotation that individuals achieve is correlated with their intel- ligence as measured by standard tests ${ }^{13}$. Pigeons were trained to perform an instrumental matching-to-sample or an oddity-from-sample discrimination task with visual forms. When then tested under conditions with the comparison shapes angularly misaligned with respect to the samples, neither their error rates nor their reaction latencies depended on the degree of stimulus orientation disparity. Among other possibilities we suggested that the species difference thus revealed might be due to the fact that, being birds, pigeons have a visual system based predominantly on the midbrain optic tectum, compared with humans who, as mammals, have a mainly endbrain, striate cortex based system ${ }^{12}$.

Correspondence: J.D. Delius, Experimentelle Tierpsychologie, Psychologisches Institut, Ruhr-Universität Bochum, D-4630 Bochum, F.R.G. 
In an attempt to clarify the differential function allocation that is implied in this hypothesis we examine here the rotation invariance performance of pigeons before and after they have been surgically deprived of a major portion of the hyperstriatum, a dorsofrontal telencephalic area also known as the Wulst, that includes the avian homologue of the mammalian visual cortex ${ }^{15}$. The selection of a neutral control lesion location was somewhat difficult but, on the basis of some preliminary findings in another context, we lesioned the dorsal neostriatum intermedium, an area that as far as it is known has no visual functions ${ }^{7}$. As the rotational invariance of pattern recognition must involve complex information processing, for the sake of comparison we also tested the animals with simple instrumental colour and shape discriminations. These latter tasks have been employed in several other forebrain lesion studies using pigeons ${ }^{6.14}$.

\section{MATERIALS AND METHODS}

Data pertaining to 6 adult homing pigeons (Columba livia) of local origin are presented. Originally, 9 subjects took part in the experiment, but one bird died during surgery and the lesions of two birds were seriously misplaced. All birds had previously participated in a series of rotational invariance experiments $\mathrm{s}^{5,12}$. The birds were maintained at approximately $85 \%$ of their normal weights throughout the experiment and kept in individual cages in a brightly lit (lights $12 \mathrm{~h}$ on, $12 \mathrm{~h}$ off) and well-ventilated animal room.

For the matching-to-sample task (henceforth, to simplify, and unless stated otherwise, this expression is to be understood as also encompassing the oddity-from-sample task) a conventional 3-key Skinner-box was employed. Stimuli were back-projected onto the keys with the and of an automatic projector. The 3-stimulus combinations (sets) were assembled with different visual forms (Fig. 1). The forms were originally drawn in black ink on white paper, and photographically reduced negatives were mounted in groups of three onto the slide frames. On the keys the forms appeared as white figures of about $10 \times 10 \mathrm{~mm}$ on a dark background of $25 \mathrm{~mm}$ diameter. The dis- play on the individual keys was controlled by shutters located directly behind the keys. Photocells within the projector detected the presence or absence of coding perforations in the slide frames. A computer controlled all events within the experimental sessions and recorded the data on a trial by trial basis with a printer.

Sessions were daily (mornings). All 40 stimulus sets based on 4 forms were presented in each session. In half of the sets the identical comparison form was displayed on the right key and in the other half on the left key, the sample form being displayed on the center key. These two kinds of sets were presented in a quasi random sequence $^{8}$. The odd comparison form that appeared on the other side-key was always the vertically reflected mirror-image of the sample. The sample form was always presented in the standard orientation shown in Fig. 1, left. In a given set both comparison forms were presented rotated by either $0,45,90,135$ or $180^{\circ}$ in a clockwise direction (Fig. 1, right). Within a session each orientation occurred 8 times. The sequence of stimulus sets was randomised and varied from session to session.

A trial began with the projection of a sample form onto the centre key. When the bird had pecked this key 15 times, the two side shutters opened and two comparison forms appeared on the side keys. Three subjects were required to peck the key displaying the identical form (matching-to-sample), the remaining were required to peck the key displaying the mirror image (oddityfrom-sample). Following a single correct side-key response, the stimuli disappeared and the bird was rewarded with a 3-s access to food. An incorrect response was followed by $3 \mathrm{~s}$ of complete darkness, the house-light being switched off as well. The time that elapsed between the onset of the comparison stimuli and the response to one of them was recorded as reaction time. After an 8 -s interval the next trial began with the presentation of the next sample stimulus.

As the birds were experienced they only needed to be retrained on the matching-to-sample task. Sets constructed with forms $1,2,3$ and 4 were used during this phase. These forms were already known to the birds $s^{12}$. The birds were retrained for 
a minimum of 11 and a maximum of 25 daily sessions with these stimulus sets, until each subject yielded at least $85 \%$ correct responses in 3 consecutive sessions. We note that there were no significant performance differences between matching-to-sample and oddity-from-sample subjects, neither here nor, as a matter of fact, during any other phase of this study. Thus, no differentiations will be made between these two treatments in the remainder of the paper.

The animals were divided in two groups matched according to the number of sessions to criterion (mean of future hyperstriatal group: 17.0 sessions, future neostriatal group: 15.6 sessions) and submitted to surgery (see below) within 1-3 days of reaching criterion. Retraining with the same stimulus sets on the rotational invariance task began on the fourth day following surgery. Training continued until a bird had reached criterion again. All birds received at least 10 sessions. When more than 10 sessions were needed a correction procedure was introduced. If a bird responded incorrectly on the previous trial then this trial was repeated until a correct response was emitted. With the end of this
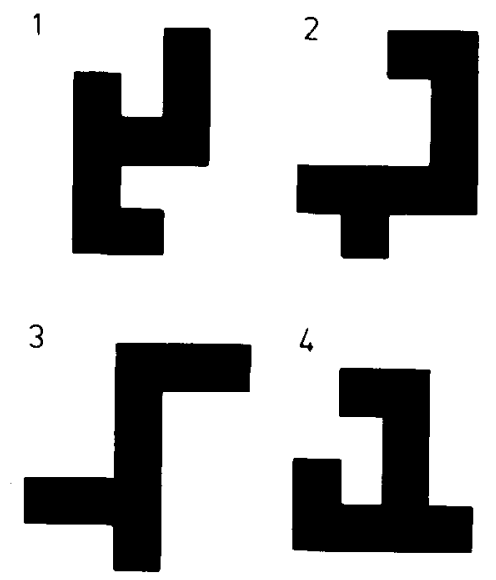

5

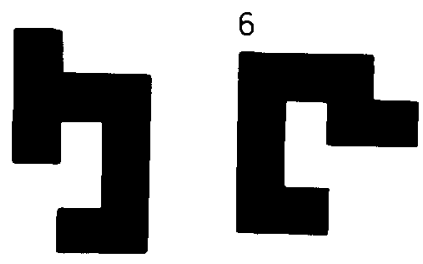

reacquisition phase the correction procedure was discontinued.

For the next phase, sets based on forms 1 and 2 were retained, but sets constructed with forms 3 and 4 were removed and replaced by sets based on the novel forms 5 and 6 (Fig. 1). Thus half of the stimulus sets were new to the animals. All birds received 10 sessions with these stimulus sets. The novel forms were then replaced again by forms 3 and 4 and the birds were retrained for 7 sessions. Following this, the birds experienced 5 sessions with a delayed matching-to-sample procedure, meaning that upon the final peck to the sample this stimulus extinguished and the comparison stimuli were not presented until $1 \mathrm{~s}$ later. This was followed by another 5 sessions with a 2-s delay.

Parallel to the matching-to-sample task, the birds also participated in daily sessions (afternoons) on a simultaneous discrimination task. Before surgery the birds were trained for a minimum of 11 sessions on a hue discrimination task using a discrete trial procedure. A conventional two-key Skinner-box was used. Yellow (Wratten filter no. 9) and orange (Wratten filter

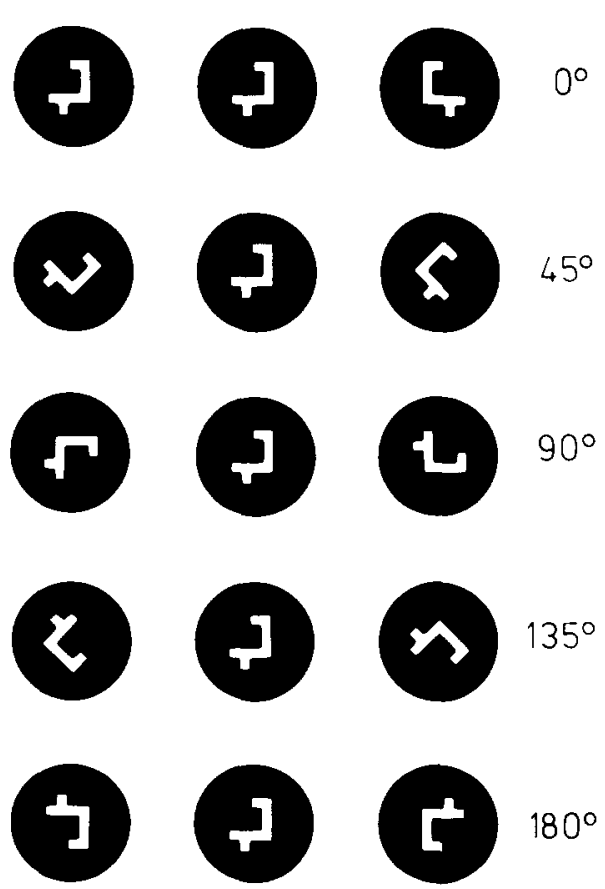

Fig. 1. Shapes employed and examples of stimulus sets used in the matching-to-sample experiment. Shapes 5 and 6 were novel to the birds. 
no. 16) lights, were back-projected on keys with the aid of multichannel in-line microprojectors. Both colour stimuli were approximately matched for equal pigeon subjective brightness with neutral density filters according to Blough' ${ }^{2}$ spectral sensitivity comparison between man and pigeon. Additionally, one or the other colour on one or the other key was randomly dimmed by 0.2 log units, making any remaining intensity differences irrelevant.

All events within a session of 32 trials were controlled by modular logic programming equipment. A trial began with the relevant stimulus pair being projected on the keys. When the animal pecked the key bearing the positive stimulus, the stimuli extinguished, food was offered for $3 \mathrm{~s}$ and the next trial began immediately afterwards, the left-right positions of the stimuli being determined by a quasi-random sequence ${ }^{8}$. If the subjects responded to the negative stimulus, the stimuli and the houselight extinguished for $16 \mathrm{~s}$ before the next trial began in which the stimulus positions were retained, thus instituting a correction procedure. Counters recorded the correct and incorrect responses disregarding correction trials. Three subjects were reinforced for responses to the yellow key, 3 subjects for responses to the orange key.

Four days after surgery, the subjects began a retraining phase on the hue discrimination that lasted 10 sessions. Then the colours were replaced by a white square and a white circle of equal surface area $\left(56 \mathrm{~mm}^{2}\right)$ and equal luminance on a dark background. For 3 birds, the square was the positive stimulus, for 3 birds the positive stimulus was the circle. Ten sessions were given on this task.

Surgery was performed while the animals were under barbiturate/chloral hydrate anaesthesia (see ref. 22 for details) and their heads were held in a stereotaxic holder ${ }^{16}$. The skull was exposed and bilaterally trephined over the target area with a dental burr. Neural tissue was removed by simple aspiration after the dura had been slit. Three birds had the anterior hyperstriatum and 3 others the dorsal neostriatum intermedium ablated.

After the behavioural testing was completed, the animals were perfused with saline and formalin. The brains were removed from the skull, embedded in egg yolk that was hardened with formalin vapors, and cut in the frontal plane with a freezing microtome at $40 \mu \mathrm{m}$. Sections at approximately $0.5-\mathrm{mm}$ intervals were mounted and stained with Cresyl violet. These were examined under a microscope and the extent of the lesions was transferred onto drawings taken from the Karten and $\mathrm{Hodos}^{16}$ pigeon brain atlas.

\section{RESULTS}

As can be seen in Fig. 2, the lesions, while affecting appreciable portions of the target areas, the various subdivisions of the hyperstriatum or the dorsal neostriatum, largely spared neighbouring structures. The volume of neural tissue damaged is closely similar for both kinds of lesions. The hyperstriatal lesions affect in each subject at least $80 \%$ of the terminal fields of the optothalamic-hyperstriatal projection as described anatomically for the pigeon by Karten et al. ${ }^{17}$. The same birds also exhibit a massive cell loss in the nucleus opticus thalami area. A more precise quantification of this latter damage, however, is not possible because the even normally poor histological definition of the nucleus is complicated in the present material by tissue deformations secondary to the degeneration. No diencephalic retrograde damage could be detected in any of the neostriatal subjects. As previously explained two further birds, whose lesions (not illustrated) had been misplaced, were excluded from closer evaluation.

For assessment of the matching-to-sample performance the percent correct responses for each session by each bird was calculated. Separate means over the 3 subjects of the hyperstriatal and neostriatal groups are shown in Fig. 3 plotted as a function of the sessions. Generally there was little disparity between the two groups and an overall analysis of variance yielded an $F_{1,4}=0.159, P>0.05$ for the treatment differences. In particular, both groups showed a closely similar temporary drop in performance after surgery. The hyperstriatal birds required an average of 14.3 postoperative sessions to reach 

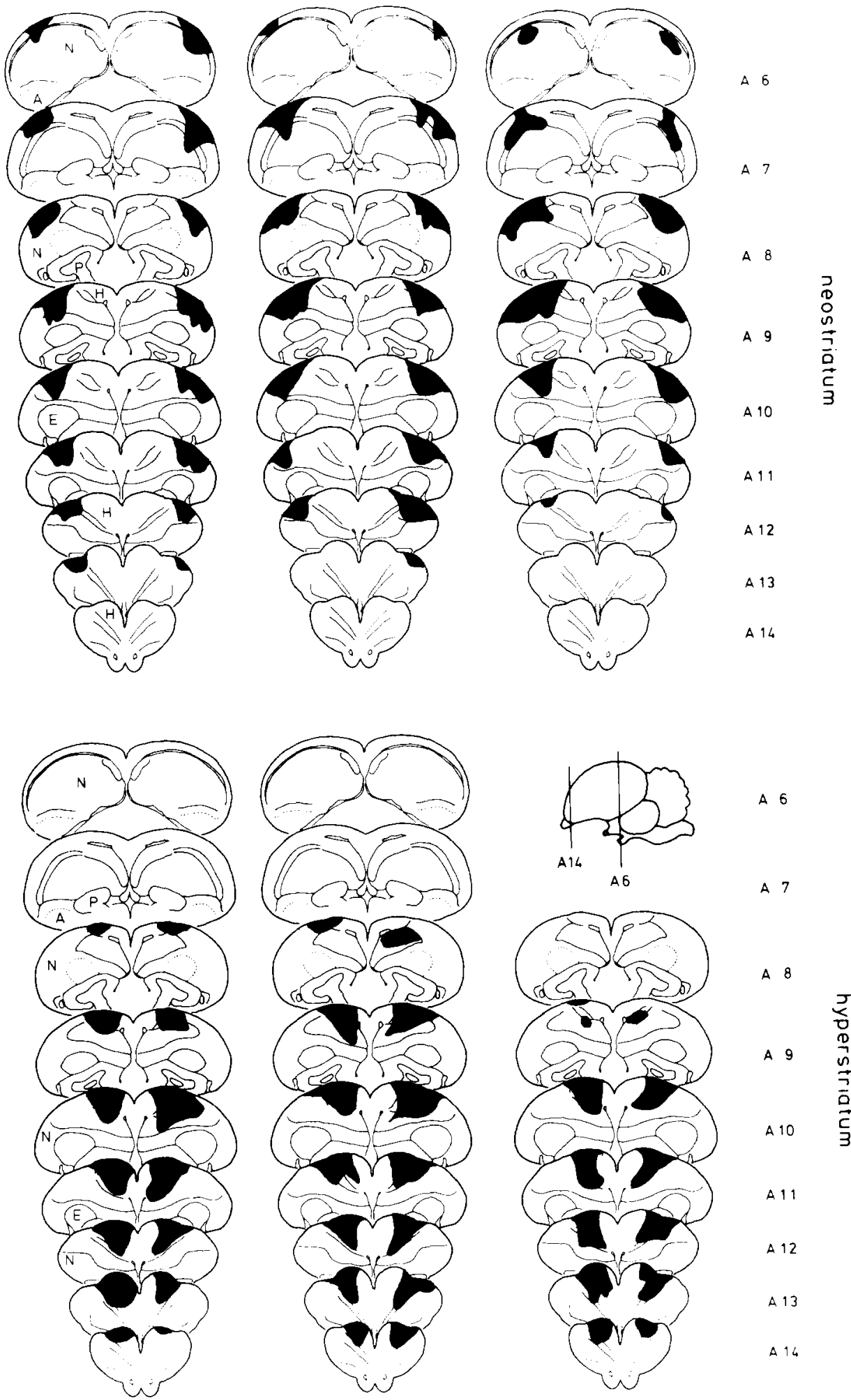

A 6

A 7
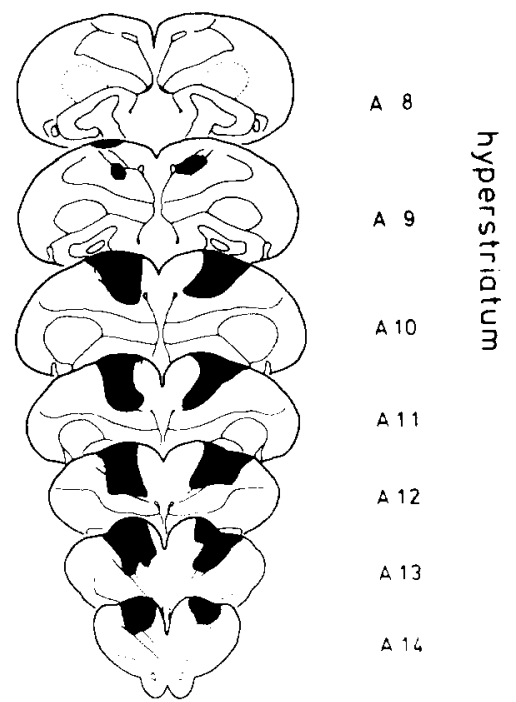

A 11

A 12

$\Delta 13$

A 14

Fig. 2. Extent of hyperstriatal (bottom) and neostriatal (top) lesions. The brain section diagrams are based on ref. 16 . A, archistriatum; E, ectostriatum; H, hyperstriatum; N, neostriatum; P, paleostriatum. 


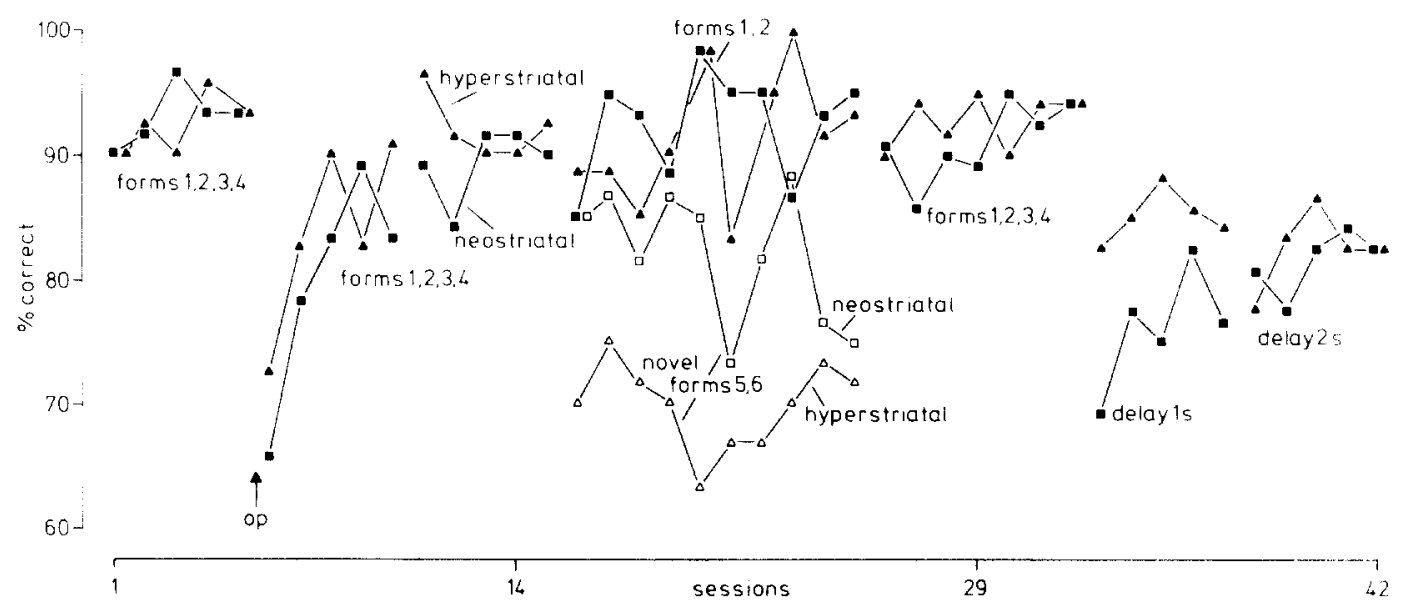

Fig. 3. Mean pre- and postoperative matching-to-sample performance of hyperstriatal (triangles) and neostriatum (squares) lesioned birds as a function of the progression of sessions. Only the last 5 sessions of the preoperative training phase, the 5 first and the 5 last sessions of the postoperative training phase are shown. Closed symbols refer to data obtained with stimulus forms 1-4 except during middle sessions when they refer to results with forms 1 and 2 . Open symbols represent data obtained with novel forms 5 and 6 .

criterium again, the neostriatal birds 18.0 sessions, but the difference is not significant.

The only difference between hyperstriatumand neostriatum-lesioned birds became apparent during the 10 sessions involving the two novel forms 5 and 6 . A separate analysis of variance on the data pertaining to these two stimuli revealed that the hyperstriatum-lesioned birds performed worse compared with the neostriatal birds $\left(F_{1,4}=7.68, P \approx 0.05\right)$. A difference between performance on the habitual and the novel stimuli was present in both groups, but it was more marked in the hyperstriatal birds $\left(F_{1,38}=30.32\right.$ and $82.42, P<0.01$ ). However both groups of pigeons performed above the $50 \%$ chance level on the very first presentation of the 20 novel sets, the hyperstriatal birds achieving $70.2 \%$ and the neostriatal birds $85.2 \%$ correct choices (binomial tests, $P<0.01$ ).

The taxing of short-term memory, intended with the introduction of a delay between sample and comparison presentations, yielded a fall in performance commensurate with that obtained in normal pigeons ${ }^{5}$, but it did not reveal a difference between the two groups of pigeons. There was a tendency for the neostriatal birds to do worse on the 1-s delay sessions but an analysis of variance indicated that the difference is not significant.

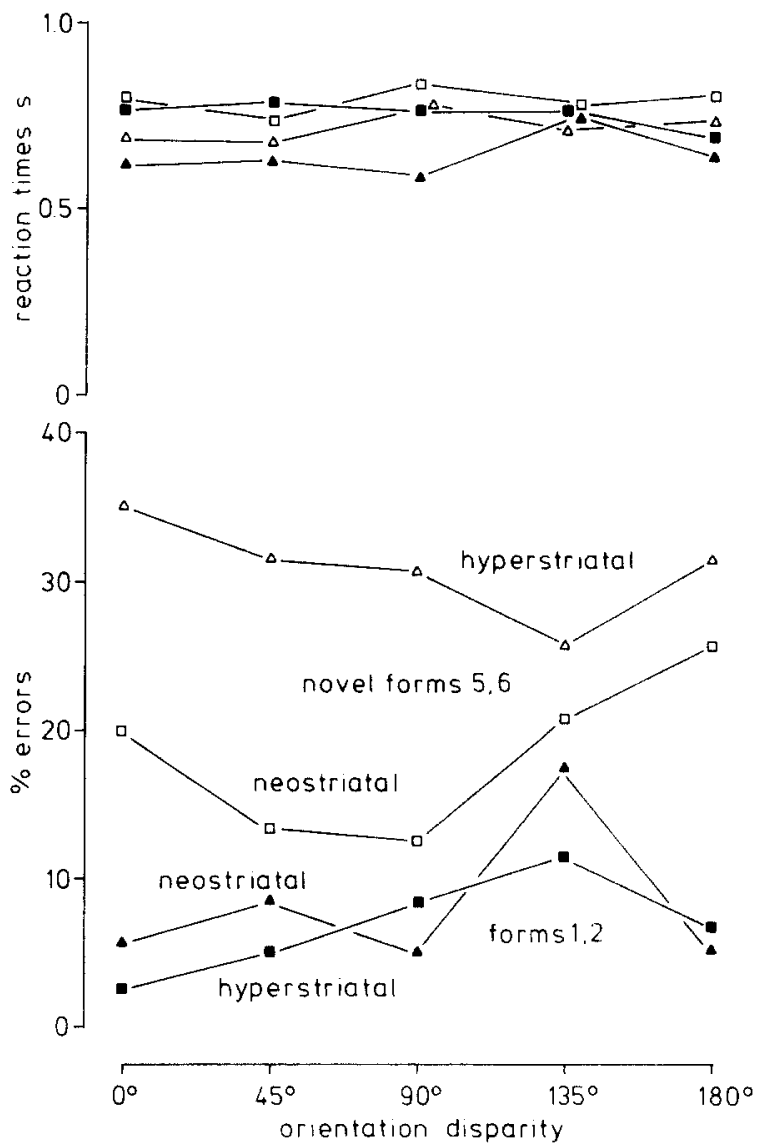

Fig. 4. Mean matching-to-sample accuracy and latency of hyperstriatum- and neostriatum-lesioned birds as a function of the angular disparity between sample and comparison shapes. 
Furthermore the difference disappeared during the final 2-s delay phase.

The rotational invariance performance during the 10 sessions involving both novel and known shapes was analysed more closely. Mean percent errors and mean reaction times were calculated for each degree of orientation disparity between sample and comparison (Fig. 4), separately for each class of stimuli and separately for the two groups of pigeons. In all cases, analyses of variance of both error rates and reaction times revealed no significant dependence on the orientation discrepancy between samples and comparisons, this being in agreement with results reported in ref. 12. As far as it concerns error rates, this analysis naturally confirmed the worse performance of the hyperstriatal pigeons on the novel sets. The reaction times, however, reveal no difference between the two types of lesions. It should be added that these postlesion reaction times, regardless of lesion type, also did not differ from the prelesion ones. It is important that when confronted with combinations of the novel shapes, incorporating orientation disparities of $45-135^{\circ}$ between samples and comparison forms, both groups exhibited above chance accuracy during the very first presentation of the relevant 16 stimulus sets (neostriatals $85.4 \%$, hyperstriatals $68.2 \%$ trials correct, binomial tests, $P<0.01$.

The performance on the simultaneous hue and shape discriminations was assessed by calculating the percent correct trials session by session. Plots of separate averages of this scores for the two groups of subjects revealed almost identical functions (Fig. 5). In particular, performance of both groups on the hue discriminations was only minimally disturbed by the surgery. There was also no difference in the postoperative acquisition of the shape discrimination. Regarding the Wulst lesions, the results replicated the findings of Delius et al. ${ }^{6}$, who concluded that hyperstriatal lesions, quite differently from lateral telencephalic lesions concerning the most lateral neostriatum intermedium, do not appreciably affect these simpler discriminations. It is comforting that the present pigeons with dorsal neostriatum lesions, intended here as control lesions, also yielded performances that coincided with the performance of sham-operated pigeons on the same tasks

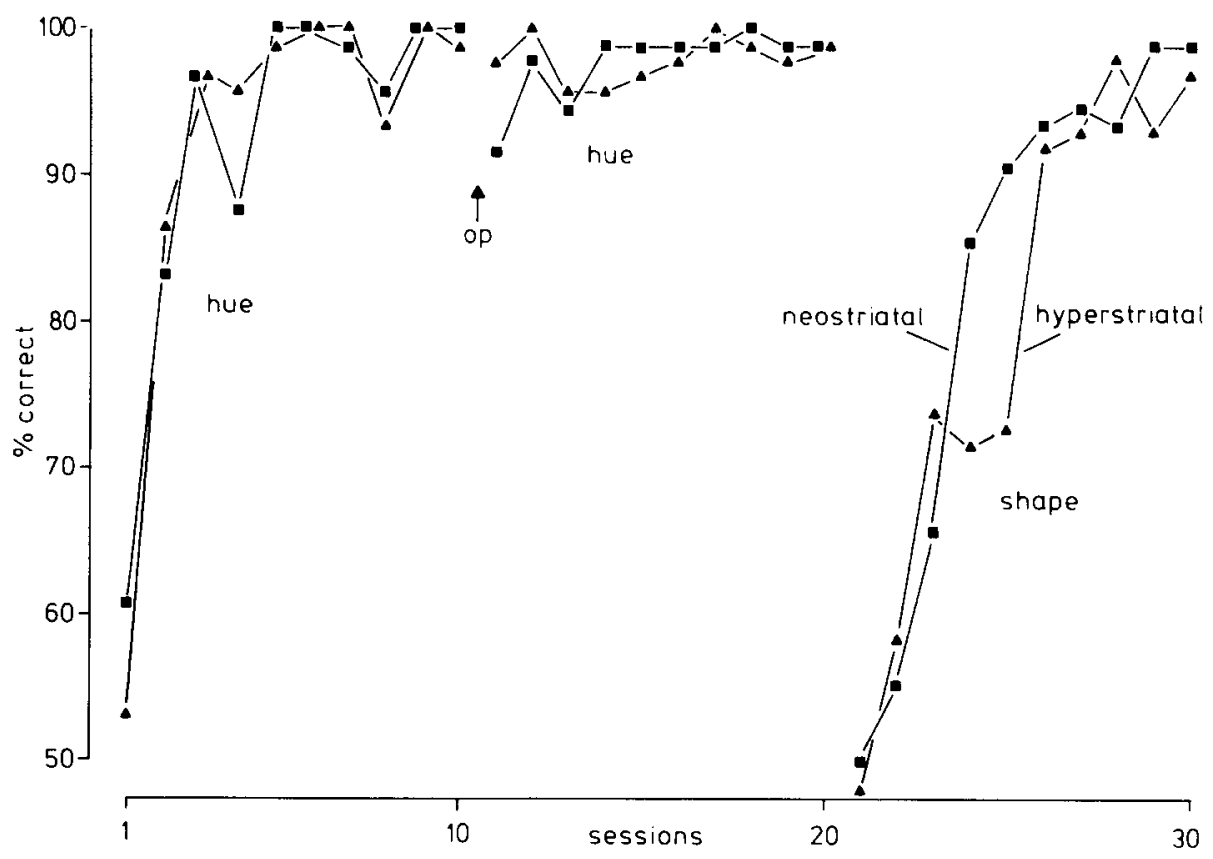

Fig. 5. Mean pre- and postoperative performance on the simultaneous discrimination of hue and shapes by hyperstriatum(triangles) and neostriatum- (squares) -lesioned birds as a function of the progression of sessions. 
reported in the above-mentioned study. The dorsal neostriatum intermedium of the pigeon may thus truly be a neutral structure as regards to visual functions.

\section{DISCUSSION}

The present experiment confirms first of all that pigeons can solve a visual matching-to-sample task on the basis of a relational, conceptual rule ${ }^{20}$. All subjects regardless of their lesions were able to transfer the performance acquired on one collection of 3 stimulus sets to another collection of sets constructed from novel stimuli (shapes 5 and 6) at above chance levels. This was not due to rapid learning, since even during the very first presentation of the 20 novel sets, that is, before reinforcement could have had any effect, the birds chose correctly well above chance level. There have been doubts about the pigeon's capacity to apply such a relational rule ${ }^{3,28}$. The present result and others that are reported in ref. 18 or reviewed in refs. 21 and 19, however, leave little doubt that, given suitable conditions, pigeons can indeed learn to behave according to an abstract same/different rule.

At the same time, the results also confirm the pigeon's ability to recognize the equivalence of visual shapes under conditions of orientation disparity as we described previously ${ }^{12}$. Even when dealing with totally novel forms for the first time, the pigeons performed at above chance levels. Some doubts about this capacity of pigeons have been expressed ${ }^{10}$, but the present results, as well as some further ones soon to be reported, ${ }^{4,5}$, again leave little doubt that when tested in adequate experimental circumstances pigeons are capable of rotational invariance during visual shape discriminations.

The brain lesions had only a minor effect on the matching-to-sample of visual shapes with rotated comparison stimuli. Postsurgery performance on the sets involving the habitual stimuli returned close to preoperative levels within a few sessions. This is remarkable as refers to the hyperstriatal lesions as these destroyed the avian homologue of the primary visual cortex of mammals. The ablation of this latter structure leaves mammals at the very least largely incapable of shape discrimination and certainly incapable of rotation invariance. Lesions of other neighbouring cortical structures that are neurally downstream from the primary visual cortex, however, seem to yield more specific perceptual invariance impairments, among them, orientation invariance deficits, at least in monkeys ${ }^{27}$.

On the other hand, regarding novel stimuli, some postoperative deficit was apparent in the hyperstriatal birds compared with the neostriatals. The performance on the novel stimuli of these latter birds was also worse than on the habitual stimuli, but decay to similar extents is also shown by unoperated birds when faced with new stimuli ${ }^{12}$. In the case of the hyperstriatals it was somewhat more pronounced. Hyperstriatal lesions, though, do not simply impair the birds' capacity to deal with novel stimuli as they showed no deficit when learning to discriminate the novel shapes in the simultaneous discrimination task. It is more probable that this lesion simply yields discrimination deficits whenever the test task is relatively difficult ${ }^{21,25}$. However, even with the novel stimuli there was no question of the hyperstriatum-lesioned pigeons dropping to chance performance on the rotation invariance task. Thus the Wulst lesions did not destroy the structure responsible for rotational invariance of pattern recognition. As a curiosity, we mention that one of the birds with unsuccessful lesions referred to earlier had an ablation affecting almost half of the endbrain volume including all of the hyperstriatum and a good deal of the ectostriatum, the other major telencephalic visual projection area of birds $^{7}$, and still showed a rotation invariance performance that was not at all worse than that of the hyperstriatal pigeons. In short, it seems unlikely that the relevant structure is located anywhere in the telencephalon.

Rather, we suspect that the rotation invariance function has to be ascribed to the tectum opticum, the major visual structure of birds. The Wulst lesions may have slightly affected the latter's functioning due to the disruption of a descending pathway known to originate in the hyperstriatum and to terminate in the tectum (septo-mesencephalic $\left.\operatorname{tract}^{1,23}\right)$. The interruption of this 
pathway has been thought to produce tectal disfunction in other contexts as well ${ }^{9,24}$. A direct test of the hypothesis that the tectum opticum implements visual rotation invariance will remain difficult as lesions of this highly complex structure render birds practically blind ${ }^{11}$. Rather, it seems that it will be necessary to look for evidence of such a function at the cellular level with electrophysiological techniques, a somewhat daunting task.

\section{ACKNOWLEDGEMENTS}

The research was supported by the Deutsche Forschungsgemeinschaft through its Sonderforschungsbereich 114. While at Bochum V.D.H. was a recipient of grants by the Heinrich HertzStiftung and the Deutscher Akademischer Austauschdienst. We are grateful to Annette Lohmann whose help was essential. We also thank D. Hagenkötter, G. Keim and U. Schall for assistance in various matters.

\section{REFERENCES}

1 Bagnoli, P., Grassi, S. and Magni, F., A direct connection between visual Wulst and tectum opticum in the pigeon (Columba livia) demonstrated by horseradish peroxidase, Arch. Ital. Biol., 118 (1980) 72-88.

2 Blough, D.S., Spectral sensitivity in the pigeon, J. Opt. Soc. Am., 47 (1957) 827-833.

3 D'Amato, M. R. and Salmon, P.D., Cognitive processes in cebus monkeys. In H.L. Roitblat, T.G. Bever and H.S. Terrace (Eds.), Animal Cognition Erlbaum, Hillsdale 1984.

4 Delius, J.D., Complex visual information processing in the pigeon, Acta 18 Congr. Internat. Ornithol., Nauka, Moscow, 2 (1985) 804-811.

5 Delius, J.D. and Hollard, V.D., Further experiments on the orientation invariance of pattern recognition in pigeons, J. Exp. Psychol. Anim. Behav. Process., in preparation.

6 Delius, J.D., Jäger, R. and Friesel, M., Lateral telencephalic lesions affect visual discrimination in pigeons, Behav. Brain Res., 11 (1984) 249-258.

7 Emmerton, J., Functional morphology of the visual system. In M. Abs (Ed.), Physiology and Behaviour of the Pigeon, Academic, London, 1983, pp. 221-244.

8 Fellows, B.J., Chance stimulus response sequences for discrimination tasks, Psychol. Bull., 67 (1967) 87-92.

9 Güntürkün, O. and Hoferichter, H.H., Neglect after section of a left telencephalotectal tract in pigeons, Behav. Brain Res., 18 (1985) 1-9.
10 Herrnstein, R.J., Riddles of natural categorization, Phil. Trans. R. Soc. London, Ser. B, 308 (1985) 129-144.

11 Hodos, W., Vision and the visual system: a bird's-eye view, Progr. Physiol. Psychol., 6 (1976) 29-62.

12 Hollard, V.D. and Delius, J.D., Rotational invariance in visual pattern recognition by pigeons and humans, Science, 218 (1982) 804-806.

13 Hunt, E., On the nature of intelligence, Science, 219 (1983) 141-146.

14 Jäger, R., Effects of unilateral forebrain lesions of brightness discrimination in the pigeon, Behav. Anal. Lett., 3 (1983) 403.

15 Karten, H.J., The organization of the avian telencephalon and some speculations on the phylogeny of the amniote telencephalon, Ann. N.Y. Acad. Sci., 167 (1969) 164-179.

16 Karten, H.J. and Hodos, W., A Stereotaxic Atlas of the Brain of the Pigeon (Columba livia), John Hopkins, Baltimore, 1967.

17 Karten, H.J., Hodos, W., Nauta, W.J.H. and Revzin, A.M., Neural connections of the 'visual Wulst' of the avian telencephalon. Experimental studies in the pigeon (Columba livia) and owl (Speotyto cunicularia), J. Comp. Neurol., 150 (1973) 253-278.

18 Lombardi, C.M. and Delius, J.D., Size invariance in visual pattern recognition by pigeons. In M.L. Commons, S.M. Kosslyn and R.J. Herrnstein (Eds.), Pattern Recognition and Concepts in Animals, People and Machines, Erlbaum, Hillsdale, in press.

19 Lombardi, C.M., Delius, J.D. and Hollard, V.D., Conceptualización de una relación logica en palomas, $R e v$. Latinoam. Psicol., 18 (1986) 277-297.

20 Lombardi, C.M., Fachinelli, C. and Delius, J.D., Oddity of visual patterns conceptualized by pigeons, Anim. Learn. Behav., 12 (1984) 2-6.

21 Macphail, E., Brain and Intelligence in Vertebrates, Clarendon, Oxford, 1982.

22 Mallin, H.D. and Delius, J.D., Inter- and intraocular transfer of colour discriminations with mandibulation as an operant in the head-fixed pigeon, Behav. Anal. Lett., 3 (1983) 415-424.

23 Mestres, P. and Delius, J.D., A contribution to the study of the afferents to the pigeon optic tectum, Anat. Embryol., 165 (1982) 415-424.

24 Nau, F. and Delius, J.D., Discrepant effects of unilateral and bilateral forebrain lesions on the visual performance of pigeons, Behav. Brain. Res., 2 (1981) 119-124.

25 Parker, D.M. and Delius, J.D., The effect of Wulst lesions on simple visual discrimination performance in the pigeon, Behav. Process., 5 (1980) 151-159.

26 Shepard, R.N. and Cooper, L.A., Mental Images and Their Transformations, MIT Press, Cambridge, MA, 1982.

27 Weiskrantz, L. and Saunders, R.C., Impairments of visual object transforms in monkeys, Brain, 107 (1984) 1033-1072.

28 Wilson, B., Mackintosh, N.J. and Boakes, R.A., Matching and oddity learning in the pigeon: transfer effects and the absence of relational learning, Q.J. Exp. Psychol., 37 (1985) 295-311. 